Case Presentation A 6.4 year old girl presented with acne, pubic hair and body odour.

Diagnosis of CPP was performed on the basis of clinical signs of central puberty (breast Tanner 2 and pubic hair Tanner 2), increased basal gonadotrophine hormones (LH $4.6 \mathrm{IU} /$ L, FSH $3.7 \mathrm{IU} / \mathrm{L}, \mathrm{E} 2109 \mathrm{pmol} / \mathrm{L}$ ) and growth spurt (height on 1.6 SDS). Her bone age was assessed to be 7 years.

Brain Magnetic Resonance (MRI) did not disclose any abnormality. Treatment with GnRHa was given subcutaneously once a month (triptorelin in a dose

$3.75 \mathrm{mg}$ ). Girl's dizygotic twin sister developed signs of puberty at the age of 8 years. At presentation, she had breast Tanner 3 and pubic hair Tanner 1. Her bone age was 8.6 years, her height was on 0.8 SDS. Laboratory assessment confirmed CPP (LH 1.07 IU/L, FSH 3.9 IU/L, E2 187 pmol/L ) and after additional endocrinological and neuroradiological work-up, suppression of CPP started. Precocious puberty was well controlled by pharmacological therapy and both sisters reached their final height $(163.8$ and $159.1 \mathrm{~cm})$ in accordance with midparental height (MPH $165 \mathrm{~cm}, 0.6 \mathrm{SDS}$ ).

As CPP was diagnosed in both dyzygotic twin sisters, we sought for a genetic cause.

Coding regions of the MKRN3 gene and exon-intron boundaries were analyzed using Sanger sequencing. Pathologic heterozygous variant NM_005664.3:3:c.475_476insC (NP_005655.1:p.Ala162Glyfs) of MKRN3 gene was identified in both siblings.

Conclusion We want to highlight the importance of genetic analysis in cases od familial CPP, providing grounds for genetic counseling in later life.

\section{TRANSIT BILATERAL CATARACT IN TWO NEWLY DIAGNOSED TYPE 1 DIABETES MELLITES IN PEDIATRIC POPULATION}

Marko Simunovic*, Martina Paradzik, Roko Skrabic, Kajo Bucan, Veselin Skrabic. University Hospital of Split

\subsection{6/archdischild-2021-europaediatrics.203}

Introduction Cataract is a rare manifestation of ocular complication at an early phase of type 1 diabetes mellites (T1DM) in the pediatric population. The prevalence of early diabetic cataract in the population varies between 0.7 and $3.4 \%$ of children and adolescents with T1DM. The occurrence of diabetic cataract in most pediatric patients is the first sign of T1DM or occurs within 6 months of diagnosis of T1DM.

Case 1: A 15.9-year-old girl presented with newly diagnosed T1DM with hyperglycemia of $21.6 \mathrm{mmol} / \mathrm{L}$, ketonemia of $6.3 \mathrm{mmol} / \mathrm{L}$, significant ketonuria and glucosuria, but without diabetic ketoacidosis ( $\mathrm{pH} 7.344$, bicarbonate $17.1 \mathrm{mmol} /$ L). She had a 2 months history of polydipsia, polyuria and 7 $\mathrm{kg}$ weight loss. Laboratory findings at admission include: haemoglobin A1c (HbA1c) of 16.9\%, C-peptide of $0.2 \mathrm{nmol} / \mathrm{L}$ and positive GAD-65, ICA-512, and IA-2 antibodies. She was treated with intensive insulin basal/bolus regimen.

On 7-day of the hospitalization patient started to have blurriness of vision. Ophthalmological examination showed 0.9 vision on both eyes and examination on the biomicroscope indicated bilateral center nuclear cataract. On 14-day almost complete transparency of lens was observed, with complete visual acuity recovery.
Case 2: A 13.53-year-old girl was admitted with 3 months history of polydipsia, polyuria, nycturia and $11 \mathrm{~kg}$ weight loss. In initial laboratory evaluation T1DM was confirmed (hyperglycemia of $26.9 \mathrm{mmol} / \mathrm{L}$, ketonemia of $5.1 \mathrm{mmol} / \mathrm{L}$, significant ketonuria and glucosuria, HbA1c 17.1\%, C-peptide $0.18 \mathrm{nmol} / \mathrm{L}$ and positive antibodies), but without sings of ketoacidosis ( $\mathrm{pH} 7.411$, bicarbonate $21.6 \mathrm{mmol} / \mathrm{L}$ ). Treatment with basal/bolus regimen was started. On 9-day of the hospitalization patient began to complain of impaired vision. Biomicroscope examination showed bilateral center nuclear cataract with visual acuity of 0.8 on both eyes. On 25-day patient had normal visual acuity, with full transparency of lens.

Conclusion Early diabetic cataract although a rare complication of T1DM population, requires an initial screening as well as continuous surveillance as a measure of prevention since it is the leading causes of visual impairment in pediatric T1DM patients, especially in patients with long-term symptoms of T1DM and high levels of HbA1c. Additional studies are needed to further explain the etiological cause and therefore improve the prevention and treatment of diabetic cataract in population of children and adolescents.

\section{CASE REPORT OF RESISTANCE TO THYROID HORMONE WUTH MUTATION TO THE THYROID $\beta$ RECEPTOR GENE}

Lizaveta Collins*, Saadia Rao, Helan Shing, Beth Mclean. East Suffolk And North Essex NHS Foundation Trust Colchester Hospital

10.1136/archdischild-2021-europaediatrics.204

Background Thyroid hormones are important for energy metabolism, the metabolism of nutrients and inorganic ions, thermogenesis, and for stimulation of growth and development of various tissues Case The baby girl, was born at 39/40 uncomplicated pregnancy, presented to prolong jaundice clinic at 19th days old, Newborn bloodspot screening at 5 days was normal. She sleeps a lot and often cries when tired.

Developmentally appropriate The blood test showed the TSH $(35.7 \mathrm{mIU} / \mathrm{L})$ and FT4 $(2.87 \mathrm{mlU} / \mathrm{L})$. Her thyroid function was monitors and remained the same for 3 months However at 4 months of age she had TSH $1.2 \mathrm{mlU} / \mathrm{L}$ and T4 $25.4 \mathrm{mlU} / \mathrm{L}$, Free T3 $16.3 \mathrm{mlU} / \mathrm{L}$ She had the fluorescent sequencing analysis which showed Thyroid hormone resistance (RTH). Heterozygous mutation in TR beta - c.1286G >A (p. Arg429GIn). The diagnosis helps to provide the genetic counselling for the family.

Conclusion Resistance to thyroid hormone (RTH) 1:40,000 live births is a rare inherited syndrome characterized by diminished response of the target tissue to thyroid hormone caused, in the majority of cases, by mutation of the thyroid hormone receptor beta (THR $\beta$ ) gene. The diagnosis of RTH is challenging for the clinician. It should be considered in a patient presenting with unexplained elevated serum free T4 (fT4), unsuppressed TSH levels and decreased serum free $\mathrm{T} 4 / \mathrm{T} 3$ ratio. The treatment decision depends on the individual characteristics of each patient. Patients with hypothyroid and hyperthyroid symptoms may require treatment with thyroid hormone and with agents such as beta blockers, antithyroid drugs and thyroid hormone analogues 